\title{
Hard water softening effect of a baby cleanser
}

This article was published in the following Dove Press journal:

Clinical, Cosmetic and Investigational Dermatology

II October 2016

Number of times this article has been viewed

Russel MWalters

Emmanuel Anim-Danso

Stephanie M Amato

Kimberly A Capone

$M$ Catherine Mack

Lorena S Telofski

David A Mays

Skin Care Research \& Development, Johnson \& Johnson Consumer Inc., Skillman, NJ, USA
Correspondence: Russel M Walters Johnson \& Johnson Consumer Inc., 199 Grandview Road, Skillman, NJ 08558, USA

Tel +l 9086353238

Fax + I 9088742615

Email rwalter2@its.jnj.com
Background: Hard water is associated with atopic dermatitis (eczema). We wanted to determine if a baby cleanser and its individual components altered free ionized calcium $\left(\mathrm{Ca}^{2+}\right)$ in a simulated hard water baby bath. For these studies, an in vitro determination of free $\mathrm{Ca}^{2+}$ in a simulated hard water baby bath, and an in vivo exploratory study of free $\mathrm{Ca}^{2+}$ absorption into skin from hard water were performed.

Methods: Free $\mathrm{Ca}^{2+}$ was measured with an ion-sensitive electrode in vitro in hard water (100-500 ppm, $\mathrm{Ca}^{2+}$ ) before and after addition of the cleanser and/or its components. In an exploratory study, absorption of $\mathrm{Ca}^{2+}$ into skin from hard water was determined in three female participants (aged 21-29 years).

Results: At an in-use dilution of $1 \%$, the test cleanser reduced free $\mathrm{Ca}^{2+}$ from $\sim 500 \mathrm{ppm}$ to $<200 \mathrm{ppm}$; a $10 \%$ in-use dilution bound virtually all free $\mathrm{Ca}^{2+}$. The anionic surfactant component contributed the most to this effect. In the exploratory in vivo study, we measured a reduction of $\sim 15 \%$ in free $\mathrm{Ca}^{2+}$ from simulated hard water over 10 minutes.

Conclusion: Baby cleansers can bind free $\mathrm{Ca}^{2+}$ and reduce the effective water hardness of bath water. Reducing the amount of free $\mathrm{Ca}^{2+}$ in the water will reduce the availability of the ion for binding to the skin. Altering or reducing free $\mathrm{Ca}^{2+}$ concentrations in bath water may be an important parameter in creating the ideal baby bath.

Keywords: bath, cleanser, hard water, infant, neonate, surfactant

\section{Introduction}

Cleansing approaches, routines, and products must be carefully considered for infants; infant skin is different from the skin of older children and adults, and continues to gradually mature in structure, composition, and function for several years after birth. ${ }^{1,2}$ The stratum corneum (SC) corneocyte cells are smaller and the SC is much thinner. ${ }^{1}$ Although infant skin is better hydrated than adult skin, it has lower concentrations of natural moisturizing factor. ${ }^{3}$ Transepidermal water loss is also higher in infants, and infant skin can both absorb and lose water at a faster rate than adult skin. ${ }^{3}$ Skin $\mathrm{pH}$ is more neutral at birth, but quickly becomes more acidic, with the skin's "acid mantle" providing a more protective barrier. ${ }^{4}$ The fact that infant skin is not fully mature may place it at greater risk for the disruption of skin barrier integrity. These differences between adult and infant skin underlie the research and guidelines on factors that constitute an ideal bath for newborns and infants. ${ }^{5}$

Water alone is limited in its ability to gently and effectively cleanse, particularly for the removal of oily or fatty substances like feces and associated enzymes. ${ }^{5-7}$ Cleansers can emulsify and dislodge oily materials, soils, and microorganisms more effectively than 
water, so that these materials can be more easily removed. ${ }^{6,8}$ Appropriately formulated mild cleansers can prevent drying of the baby's skin and help support the development of the skin's natural $\mathrm{pH} .{ }^{5,9}$ Guidelines and expert opinion indicate that infant skin should be cleansed with mild liquid cleansers that are neutral in $\mathrm{pH}$ or mildly acidic ( $\mathrm{pH} 5.5-7.0),{ }^{5,6,9-11}$ or with those that have minimal impact on the baby's skin surface $\mathrm{pH}^{8,9,12}$ and have a record of safety. ${ }^{6,9,13} \mathrm{~A}$ warm $\left(\sim 105^{\circ} \mathrm{F}\right)$ immersion bath (as opposed to a sponge bath), ideally 2 hours after birth, when the infant is stable (thermal, cardiorespiratory), with a mild cleanser that does not disrupt the skin barrier has been found to be a good first bath for newborns. ${ }^{14-16}$

Hard water has been defined by the US Geological Survey as water containing divalent cations, primarily ionized calcium $\left(\mathrm{Ca}^{2+}\right)$ and magnesium $\left(\mathrm{Mg}^{2+}\right)$ at concentrations $>120$ ppm. ${ }^{17}$ Water hardness varies by geography and mineral content of the water supply. ${ }^{17,18}$ Several observational studies suggest that hard water is associated with the development of atopic dermatitis (AD). ${ }^{19-24}$ Although the relationship between water hardness and AD is not well characterized, reducing water hardness may help in reducing the potential for developing AD. In an arm washing study with different solid bars (sodium soap, triethanolamine soap, and synthetic detergent bar), harder water was found to be more irritating. ${ }^{19}$

Some common surfactants (soaps, sodium dodecyl sulfate, and polydisperse nonylphenol polyethoxylate [Igepal CO-660, Solvay, Brussels, Belgium]) are known to interact with $\mathrm{Ca}^{2+}$ and $\mathrm{Mg}^{2+}$ ions present in hard water, resulting in precipitation of the surfactant, alteration of micelle behavior, and potentially altering the composition of the solution. ${ }^{25-30}$ The aim of this study was to investigate whether cleansers formulated for use in a baby bath have the potential to alter the free $\mathrm{Ca}^{2+}$ in the bath and reduce the effective water hardness, thereby improving bath conditions.

\section{Methods}

\section{Materials}

In order to simulate baby bath water, a solution of deionized water and calcium chloride $\left(\mathrm{CaCl}_{2}\right)$ was created at various concentrations to reach water hardness equivalents between 100 and $500 \mathrm{ppm}$. Calcium chloride salt was obtained from Sigma-Aldrich (St Louis, MO, USA). Molar concentrations of calcium chloride solutions were obtained from Ricca Chemical Company (Arlington, TX, USA).

\section{Test solutions}

Three test cleansers (commercial baby wash products) and four individual ingredients, components of the test cleaners, were tested for their $\mathrm{Ca}^{+2}$ binding. The three test cleansers were obtained from www.drugstore.com (USA): Johnson's ${ }^{\circledR}$ Head-To-Toe ${ }^{\circledR}$ Baby Wash (HTT; Johnson \& Johnson Consumer Inc., Skillman, NJ, USA), Burt's Bees ${ }^{\circledR}$ (BB; Burt's Bees Baby Bee Shampoo \& Wash, Durham, NC, USA), and California Baby ${ }^{\circledR}$ (CB; California Baby Super Sensitive ${ }^{\text {TM }}$ Shampoo \& Bodywash, Los Angeles, CA, USA). As stated on the label, HTT contained water, cocamidopropyl betaine (CAPB), polyethylene glycol (PEG)-80 sorbitan laurate, sodium laureth sulfate (SLES), PEG-150 distearate, glycerin, polyquaternium-10, tetrasodium ethylenediaminetetraacetic acid (EDTA), citric acid, sodium hydroxide, sodium benzoate, ethylhexylglycerin, phenoxyethanol, and fragrance. Four individual components as aqueous solutions, made using deionized water, were also tested: SLES, PEG-80 sorbitan laurate (PEG80SL), EDTA, and decyl glucoside (obtained from Sigma-Aldrich). Additionally, a four component aqueous solution comprising SLES, CAPB, and PEG80SL (SLES/CAPB/ PEG80SL) in a 1:1:1 weight ratio was created and tested.

\section{Calcium measurements}

All measurements were performed using a Mettler-Toledo DC420 calcium-selective electrode and Mettler-Toledo S47-K SevenMulti ${ }^{\mathrm{TM}}$ with ion-selective expansion unit (MettlerToledo, LLC, Columbus, OH, USA). The probe was calibrated with commercially prepared calcium carbonate molar solutions (Sigma-Aldrich) from 10 to $1,000 \mathrm{ppm} \mathrm{Ca}^{2+}$ ions. Stirring and measurement were done at room temperature. For measurements, the calcium probe was lowered into the glass beaker $(50 \mathrm{~mL})$ containing the test solution, and the concentration was recorded continuously. A reading was obtained when the measurement had stabilized, usually after 30 seconds.

\section{In vitro}

The effect of the test cleansers on apparent $\mathrm{Ca}^{2+}$ ion concentrations in solution were made after adding the test cleansers at typical in-use cleanser dilutions of $1 \%$ and $10 \%$ concentration in deionized water containing 100, 200, 300, and $500 \mathrm{ppm} \mathrm{Ca}^{2+}$. EDTA and test cleanser components were also tested at typical in-use dilutions of $1 \%$ and $10 \%$ relative to their concentration in commercially supplied test cleansers using 200 and 500 ppm $\mathrm{Ca}^{2+}$ ion solutions. EDTA is typically used at a concentration of $0.5 \%$ in products. In this study, EDTA was tested at a dilution of $1 \%$ and $10 \%$ of the $0.5 \%$ stock solution ( $0.05 \mathrm{wt} \%$ and $0.005 \mathrm{wt} \%$ of EDTA). Surfactants in typical baby cleansers are about $10 \mathrm{wt} \%$ active. Individual surfactant or combinations of surfactants were tested at $1 \%$ and $10 \%$ dilutions of $10 \%$ solution $(0.1 \mathrm{wt} \%$ and $1.0 \mathrm{wt} \%$ of surfactant). Each solution was independently created and measured twice. 


\section{In vivo}

After providing verbal consent to participate, an exploratory pilot study was performed in three female participants (coauthors $\mathrm{KC}, \mathrm{MCM}$, and SA, aged 21-29 years) to determine the absorption of $\mathrm{Ca}^{2+}$ ions into the skin from a simulated baby bath. The authors did not obtain IRB approval for the in-vivo aspect of the study. It was very exploratory in nature and was carried out by the three authors who conceived of the specific experiments, and who are acknowledged as the participants/subjects. Simulated bath water containing 200 and $500 \mathrm{ppm}$ free $\mathrm{Ca}^{2+}$ ions was placed on the skin of the volar forearm over a diameter of $2.5 \mathrm{~cm}$ (an area of $\left.4.9 \mathrm{~cm}^{2}\right)$ in a volume of 25 or $50 \mathrm{~mL}$ in a glass vial (Fisher Scientific, Waltham, MA, USA). Separate chambers were used for each sampling time of 1,5 , or 10 minutes. The bath solution was added to the chamber and the skin of the arm was pressed against the open top of the chamber (held in place by the participant's other hand). The participant's arm was then rotated over so that the solution was against the skin. After the indicated time $(1,5$, or 10 minutes), the arm and chamber were rotated back over and the entire sample, in the chamber, was removed from the skin, and then the free $\mathrm{Ca}^{2+}$ ion in solution was determined by placing the ion-selective probe into the chamber. An additional larger $50 \mathrm{~mL}$ chamber was used for a 10 minute exposure to confirm the findings from the $25 \mathrm{~mL}$ chamber. This volume provided a larger reservoir of $\mathrm{Ca}^{2+}$ to control for possible depletion of the supply of $\mathrm{Ca}^{2+}$ available for absorption by the skin.

Concentrations were monitored for up to 10 minutes as the recommended length of a newborn baby bath is $5-10$ minutes. ${ }^{9}$ Absolute free $\mathrm{Ca}^{2+}$ concentrations as well as change from baseline concentrations were determined. Each exposure was repeated three times for each participant, and the mean concentration for each exposure was recorded.

Reduction in $\mathrm{Ca}^{2+}$ from donor solution was assumed to be due to absorption into the skin. The differences between starting concentration and ending concentration at the different time points were reported as a positive absorption per area of skin exposed $\left(\mathrm{mg} / \mathrm{mm}^{2}\right)$.

\section{Results}

\section{In vitro effect of test cleansers and their components on free $\mathrm{Ca}^{2+}$ concentrations in a simulated baby bath}

At typical in-use cleanser dilutions of $1 \%$ and $10 \%$, the HTT test cleanser reduced measured free $\mathrm{Ca}^{2+}$ in solution at all tested calcium concentrations (Figure 1). The effect of HTT test cleanser components on free $\mathrm{Ca}^{2+}$ ion in solution are

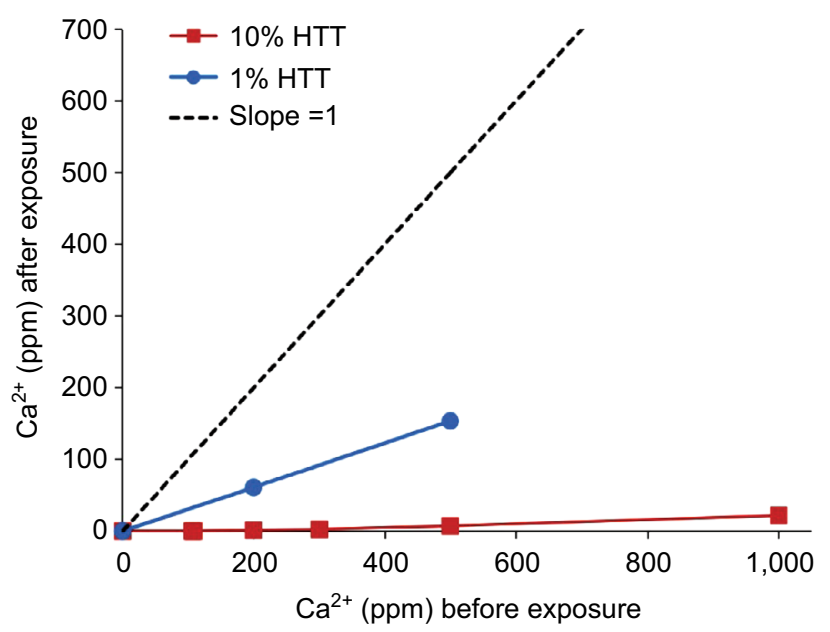

Figure I Effect of $\mathrm{HTT}$ at $1 \%$ and $10 \%$ dilution on calcium concentration in simulated baby bath.

Notes: The dotted line with slope $=I$ illustrates the starting conditions. HTT = Johnson's ${ }^{\circledR}$ Head-To-Toe ${ }^{\circledR}$ Baby wash (Johnson \& Johnson Consumer Inc., Skillman, NJ, USA).

Abbreviation: $\mathrm{Ca}^{2+}$, ionized calcium.

shown after an in-use dilution in simulated bath water of $1 \%$ (Figure 2A) and 10\% (Figure 2B). EDTA had only a slight effect on free $\mathrm{Ca}^{2+}$ ion in solution. The surfactant component SLES appeared to have the greatest effect on free $\mathrm{Ca}^{2+}$. At the $1 \%$ in-use dilution, the SLES/CAPB/PEG80SL solution had an effective concentration of $0.33 \mathrm{wt} \%$ SLES, $0.33 \mathrm{wt} \%$ CAPB, and 0.33 wt $\%$ PEG80SL. The 1:1:1 blend resulted in a lower SLES concentration in the final solution, and correspondingly less of an effect on free $\mathrm{Ca}^{2+}$ (Figure 2A). At a $10 \%$ in-use dilution, the SLES/CAPB/PEG80SL solution had an effective concentration of $3.3 \mathrm{wt} \%$ SLES, $3.3 \mathrm{wt} \%$ CAPB, and $3.3 \mathrm{wt} \%$ PEG80SL, and reduced free $\mathrm{Ca}^{2+}$ to 17 and $289 \mathrm{ppm}$ from the 200 and $500 \mathrm{ppm}^{-\mathrm{CaCl}_{2}}$ water solutions, respectively (Figure 2B).

HTT, CB, and BB were evaluated at a $10 \%$ dilution in a simulated baby bath containing 200 and $500 \mathrm{ppm}$ free $\mathrm{Ca}^{2+}$ (Figure 2B). HTT reduced free $\mathrm{Ca}^{2+}$ to 29 and $4.9 \mathrm{ppm}$ in 200 and $500 \mathrm{ppm} \mathrm{CaCl}_{2}$ test solutions, respectively. $\mathrm{CB}$ was as effective as HTT in reducing free $\mathrm{Ca}^{2+}$ to 0.8 and $2.0 \mathrm{ppm}$. $\mathrm{BB}$ and decyl glucoside alone (a component of $\mathrm{CB}$ and $\mathrm{BB}$ ) had similar efficacy and reduced free $\mathrm{Ca}^{2+}$ to $103 \mathrm{ppm}$ in the $200 \mathrm{ppm} \mathrm{CaCl}_{2}$ test solution and $136 \mathrm{ppm}$ in the $500 \mathrm{ppm}$ $\mathrm{CaCl}_{2}$ test solution.

\section{In vivo absorption of calcium into skin}

Exposure of $\mathrm{Ca}^{2+}$-containing simulated baby bath to skin for up to 10 minutes ( 600 seconds) in adult volunteers resulted in a reduction of free $\mathrm{Ca}^{2+}$ in solution, presumably through absorption into the skin (Figure 3A). The absorption of $\mathrm{Ca}^{2+}$ was similar from both 25 and $50 \mathrm{~mL}$ exposure chambers, 

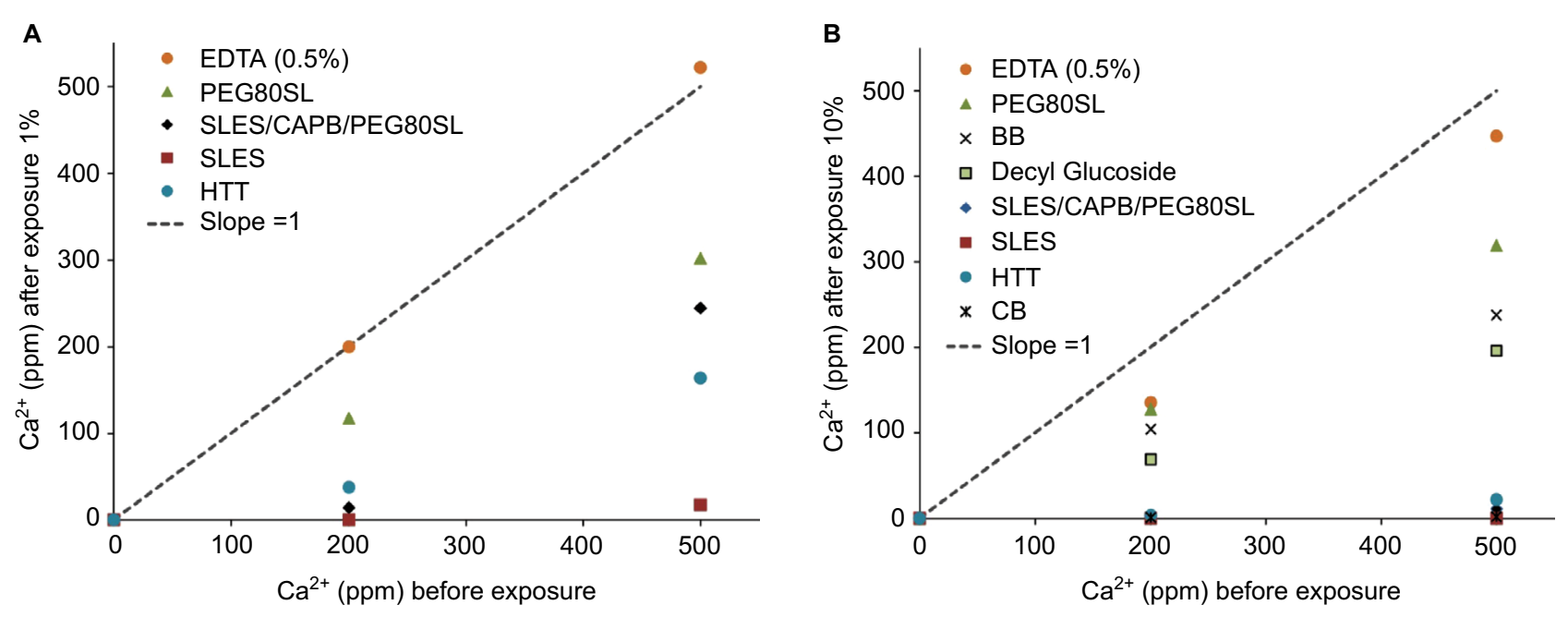

Figure 2 The effect of HTT cleanser components on free $\mathrm{Ca}^{2+}$ ion in solution.

Notes: (A) In-use dilution I\% and (B) 10\%. The line with slope $=1$ illustrates the starting conditions. BB= Burt's Bees ${ }^{\circledR}$ (Burt's Bees Baby Bee Shampoo \& Wash, Durham, NC, USA). HTT= Johnson's ${ }^{\circledR}$ Head-To-Toe ${ }^{\circledR}$ Baby Wash (Johnson \& Johnson Consumer Inc., Skillman, NJ, USA. CB= California Baby ${ }^{\circledR}$ Super Sensitive ${ }^{\mathrm{TM}}$ Shampoo \& Bodywash (Los Angeles, CA, USA).

Abbreviations: $\mathrm{Ca}^{2+}$, ionized calcium; EDTA, ethylenediaminetetraacetic acid; PEG80SL, PEG-80 sorbitan laurate; SLES, sodium laureth sulfate; SLES/CAPB/PEG80SL, sodium laureth sulfate, cocamidopropyl betaine, and PEG-80 sorbitan laurate in a I:I:I weight ratio.

A

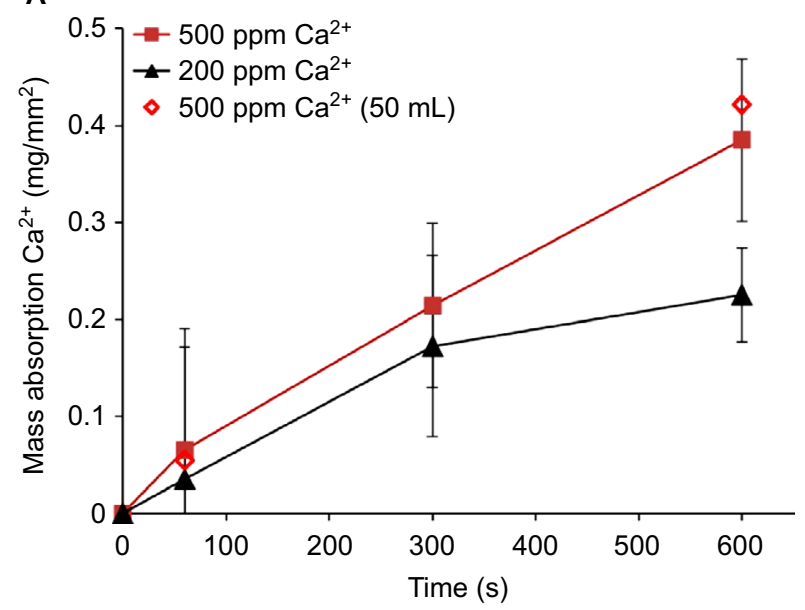

B

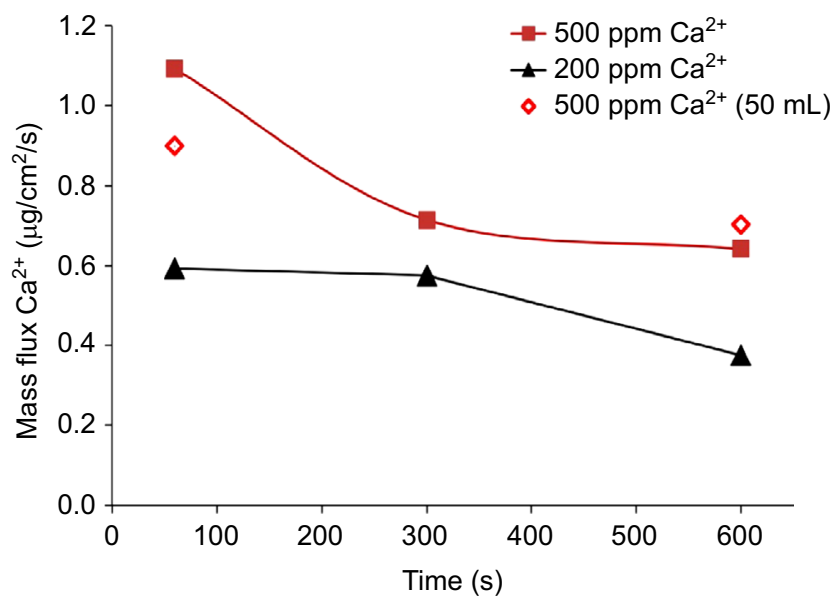

Figure 3 Absorption of $\mathrm{Ca}^{2+}$ from donor solutions into volar forearm skin of human volunteers.

Notes: (A) Mass flux ( \pm standard deviation) into the skin per $\mathrm{mm}^{2}$ exposed area. (B) Mass flux per second. Closed symbols are from $25 \mathrm{~mL}$ chambers. Open symbols are from $50 \mathrm{~mL}$ chambers.

Abbreviation: $\mathrm{Ca}^{2+}$, ionized calcium.

demonstrating that the free $\mathrm{Ca}^{2+}$ in solution was not being depleted in the smaller chamber. For 200 and $500 \mathrm{ppm} \mathrm{Ca}^{2+}$ solutions, the amount of $\mathrm{Ca}^{2+}$ that absorbed into the skin increased with time across the 10 minute test period. $\mathrm{Ca}^{2+}$ absorption appeared to occur faster from the $500 \mathrm{ppm}$ solution compared with the $200 \mathrm{ppm}$ solution.

The driving force for absorption of $\mathrm{Ca}^{2+}$ into the skin decreased over the time course of the experiment (Figure 3B). The flux of $\mathrm{Ca}^{2+}$ into the skin decreased slightly over time for the 200 and 500 ppm $\mathrm{Ca}^{2+}$ solutions. As $\mathrm{Ca}^{2+}$ absorbed into the skin, the concentration in the source solution decreased over the time course of the experiment. At 10 minutes
(600 seconds), the $\mathrm{Ca}^{2+}$ concentration was $\sim 15 \%$ lower than the initial $\mathrm{Ca}^{2+}$ concentration.

\section{Discussion}

This study demonstrated that specially formulated baby cleansers can reduce free $\mathrm{Ca}^{2+}$ and thus reduce water hardness of bath water. HTT and CB at in-use dilutions of $1 \%$ and $10 \%$ were the most effective of the tested cleansers in reducing free $\mathrm{Ca}^{2+}$ in defined hard water solutions. The surfactant components of HTT, SLES, and PEG80SL appeared to be responsible for the majority of the effect of HTT on $\mathrm{Ca}^{2+}$. CB provided reductions in free $\mathrm{Ca}^{2+}$ similar to those observed 
with HTT. BB reduced free $\mathrm{Ca}^{2+}$, but was not as effective as HTT or CB. Unexpectedly, EDTA alone, a well-known chelator of calcium, did not have much impact on free $\mathrm{Ca}^{2+}$ at the concentrations used in this study.

In vivo, it was observed that higher concentrations of free $\mathrm{Ca}^{2+}$ in water were associated with higher rates of $\mathrm{Ca}^{2+}$ absorption into the skin surface in adults. Thus, bathing in hard water in the absence of a cleanser might result in excess calcium absorption into the skin. The implications of this process for skin health is unclear, however, as the properties of adult and pediatric skin are different. In use (during cleansing and/or in the bath), $\mathrm{Ca}^{2+}$ is likely held within a complex of surfactant molecules. Synthetic detergents, such as alkyl sulfates, form stable soluble complexes with $\mathrm{Ca}^{2+, 31,32}$ (over certain concentration ranges of $\left.\mathrm{Ca}^{2+}\right)^{33}$ and, unlike bar soaps, do not form insoluble complexes that come out of solution and produce soap scum. Furthermore, the addition of the ethylene oxide to alkyl sulfate (eg, SLES) further increases the solubility in hard water. ${ }^{34}$ As this $\mathrm{Ca}^{2+}$ complex remains stable in solution, the $\mathrm{Ca}^{2+}$ is likely to be washed away during rinsing. Thereby, the $\mathrm{Ca}^{2+}$ likely does not end up on or in the skin after the cleansing, as can happen during washing with soap. Reducing the amount of free $\mathrm{Ca}^{2+}$ in bath water could thereby reduce exposure of the skin to the uncomplexed $\mathrm{Ca}^{2+}$ ion.

Increased exposure to $\mathrm{Ca}^{2+}$ may interfere with normal epidermal calcium distribution/calcium gradient. Normal calcium gradient has been shown to be necessary for terminal differentiation of corneocytes and SC barrier formation. ${ }^{35-37}$ Interference with skin-barrier formation may be related to development of susceptibility for skin irritation in the presence of hard water. ${ }^{19-21,24}$

In the US, geological survey data indicate significant variation in water hardness, with hard water $\left(\mathrm{CaCl}_{2} 121-180 \mathrm{mg} / \mathrm{L}\right)$ generally localized to the Midwestern states and very hard water $\left(\mathrm{CaCl}_{2} 181-250 \mathrm{mg} / \mathrm{L}\right)$ generally localized to the Upper Plains and Rocky Mountain areas. ${ }^{17}$ Similarly, hard water is found in many areas throughout the world. ${ }^{18}$

Several studies have demonstrated an association between hard water and the incidence of AD. McNally et al studied atopic eczema prevalence in primary school-aged children in the UK and found a positive association between prevalence of atopic eczema and water hardness. ${ }^{23}$ No significant association was seen in secondary school-aged children, leading the authors to speculate that the risk was greater in younger children. Similar increased risk of this disease in areas of hard water exposure was noted in Japanese and Spanish children. ${ }^{21,22}$ The increased susceptibility of younger children to develop $\mathrm{AD}$ in the presence of hard water suggested that there might be a critical window of opportunity to protect skin integrity/skin health over the long term, and that hard water softening may offer the most benefit for younger children.

There are only a few studies that attempted to directly evaluate the effect of hard water exposure on AD. In one study in which ion exchange water softeners were installed in participants' homes, no consistent evidence was presented that hard water softening could reduce the incidence of eczema in areas with naturally hard water. ${ }^{38-40}$ In another study, ion exchange water softening systems (replacing $\mathrm{Ca}^{2+}$ and $\mathrm{Mg}^{2+}$ with sodium ions) were installed in participants' homes for 12 weeks, again with little effect on their eczema symptoms or amount of drug usage (eg, steroids, calcineurin inhibitors). ${ }^{38,39}$ However, a more recent, 6-week, blinded crossover study in participants with less severe AD did show significant symptom improvement ${ }^{40}$ after installation of an ion exchange water softening system compared with a placebo system, suggesting a possible benefit in participants with moderate severity of disease. The latter study suggests, but does not prove, that reducing water hardness may improve AD. Additional studies must be performed to confirm a possible effect of hard water on $\mathrm{AD}$.

\section{Conclusion}

Altering or reducing free $\mathrm{Ca}^{2+}$ concentrations in bath water is an additional parameter in creating the ideal baby bath. Although the relationship between water hardness and development of AD is not well characterized, water softening properties of cleansers may help reduce water hardness that the skin experiences. Additional studies are needed to identify the contribution of specific ingredients, combinations of ingredients, and formulation parameters to achieve water softening in typical baby bath conditions. Also, a larger clinical study is needed to confirm a possible benefit to the skin of cleanser-induced water softening in bath water.

\section{Acknowledgments}

Medical writing and editorial assistance were provided by Alex Loeb, PhD, CMPP, Evidence Scientific Solutions, Philadelphia, PA, USA, and was funded by Johnson \& Johnson Consumer Inc.

\section{Disclosure}

These studies were fully supported by Johnson \& Johnson Consumer Inc., Skillman, NJ, USA. The authors report no other conflicts of interest in this work.

\section{References}

1. Stamatas GN, Nikolovski J, Luedtke MA, Kollias N, Wiegand BC. Infant skin microstructure assessed in vivo differs from adult skin in organization and at the cellular level. Pediatr Dermatol. 2010;27(2):125-131. 
2. Lund C, Kuller J, Lane A, Lott JW, Raines DA. Neonatal skin care: the scientific basis for practice. J Obstet Gynecol Neonatal Nurs. 1999; 28(3):241-254.

3. Nikolovski J, Stamatas GN, Kollias N, Wiegand BC. Barrier function and water-holding and transport properties of infant stratum corneum are different from adult and continue to develop through the first year of life. J Invest Dermatol. 2008;128(7):1728-1736.

4. Kanti V, Bonzel A, Stroux A, et al. Postnatal maturation of skin barrier function in premature infants. Skin Pharmacol Physiol. 2014;27(5): 234-241.

5. Blume-Peytavi U, Lavender T, Jenerowicz D, et al. Recommendations from a European roundtable meeting on best practice healthy infant skin care. Pediatr Dermatol. 2016;33(3):311-321.

6. Blume-Peytavi U, Hauser M, Stamatas GN, Pathirana D, Garcia Bartels N. Skin care practices for newborns and infants: review of the clinical evidence for best practices. Pediatr Dermatol. 2012;29(1):1-14.

7. Walters R, Fevola M, LiBrizzi J, Martin K. Designing cleansers for the unique needs of baby skin. Cosm Toil. 2008;123(12):53-60.

8. Kuehl BL, Fyfe KS, Shear NH. Cutaneous cleansers. Skin Therapy Lett. 2003;8(3):1-4.

9. Blume-Peytavi U, Cork MJ, Faergemann J, Szczapa J, Vanaclocha F, Gelmetti C. Bathing and cleansing in newborns from day 1 to first year of life: recommendations from a European round table meeting. J Eur Acad Dermatol Venereol. 2009;23(7):751-759.

10. Lund CH, Kuller J, Lane AT, Lott JW, Raines DA, Thomas KK. Neonatal skin care: evaluation of the AWHONN/NANN research-based practice project on knowledge and skin care practices. Association of Women's Health, Obstetric and Neonatal Nurses/National Association of Neonatal Nurses. J Obstet Gynecol Neonatal Nurs. 2001;30(1):30-40.

11. Association of Women's Health Obstetric and Neonatal Nurses. Neonatal Skin Care: Evidence-based Clinical Practice Guideline. 3rd ed. Washington, DC: Association of Women's Health, Obstetric and Neonatal Nurses; 2013.

12. Gfatter R, Hackl P, Braun F. Effects of soap and detergents on skin surface $\mathrm{pH}$, stratum corneum hydration and fat content in infants. Dermatology. 1997;195(3):258-262.

13. Dizon MV, Galzote C, Estanislao R, Mathew N, Sarkar R. Tolerance of baby cleansers in infants: a randomized controlled trial. Indian Pediatr. 2010;47(11):959-963.

14. Varda KE, Behnke RS. The effect of timing of initial bath on newborn's temperature. J Obstet Gynecol Neonatal Nurs. 2000;29(1):27-32.

15. Loring C, Gregory K, Gargan B, et al. Tub bathing improves thermoregulation of the late preterm infant. J Obstet Gynecol Neonatal Nurs. 2012; 41(2):171-179.

16. Bryanton J, Walsh D, Barrett M, Gaudet D. Tub bathing versus traditional sponge bathing for the newborn. J Obstet Gynecol Neonatal Nurs. 2004; 33(6):704-712.

17. United States Geological Survey Office of Water Safety. Water Hardness and Alkalinity; 2012. Available from: http://water.usgs.gov/owq/ hardness-alkalinity.html. Accessed April 3, 2013.

18. United Nations Environment Programme Global Environment Monitoring System/Water Programme. Water Quality for Ecosystem and Human Health; 2008. Available from: http://www.unwater.org/wwd10/ downloads/water_quality_human_health.pdf. Accessed February 19, 2015.

19. Warren R, Ertel KD, Bartolo RG, Levine MJ, Bryant PB, Wong LF. The influence of hard water (calcium) and surfactants on irritant contact dermatitis. Contact Dermatitis. 1996;35(6):337-343.

20. Tsai TF, Maibach HI. How irritant is water? An overview. Contact Dermatitis. 1999;41(6):311-314.
21. Arnedo-Pena A, Bellido-Blasco J, Puig-Barbera J, et al. [Domestic water hardness and prevalence of atopic eczema in Castellon (Spain) school children]. Salud Publica Mex. 2007;49(4):295-301. Spanish.

22. Miyake Y, Yokoyama T, Yura A, Iki M, Shimizu T. Ecological association of water hardness with prevalence of childhood atopic dermatitis in a Japanese urban area. Environ Res. 2004;94(1):33-37.

23. McNally NJ, Williams HC, Phillips DR, et al. Atopic eczema and domestic water hardness. Lancet. 1998;352(9127):527-531.

24. Osborne DW. Hard water and skin irritation. J Am Acad Dermatol. 1987;16(6):1263-1264.

25. Hu P, Tuvell M. Effect of water hardness ions on the solution properties of an anionic surfactant. J Am Oil Chem Soc. 1988;65(8):1340-1345.

26. Parkhurst HJ. Toilet soaps, soap substitutes and hard water: A study of various combinations by patch tests. Arch Dermatol Syphilol. 1941; 43(2):299-310.

27. Rodriguez CH, Chintanasathien C, Scamehorn JF, Saiwan C, Chavadej S. Precipitation in solutions containing mixtures of synthetic anionic surfactant and soap. I. Effect of sodium octanoate on hardness tolerance of sodium dodecyl sulfate. J Surfactants Deterg. 1998;1(3): 321-328.

28. Sammalkorpi M, Karttunen M, Haataja M. Ionic surfactant aggregates in saline solutions: sodium dodecyl sulfate (SDS) in the presence of excess sodium chloride $(\mathrm{NaCl})$ or calcium chloride $\left(\mathrm{CaCl}_{2}\right)$. J Phys Chem B. 2009;113(17):5863-5870.

29. Stellner KL, Scamehorn JF. Hardness tolerance of anionic surfactant solutions. 1. Anionic surfactant with added monovalent electrolyte. Langmuir. 1989;5(1):70-77.

30. Stellner KL, Scamehorn JF. Hardness tolerance of anionic surfactant solutions. 2. Effect of added nonionic surfactant. Langmuir. 1989; 5(1):77-84.

31. Draelos Z. Cosmetics and Dermatologic Problems and Solutions. 3rd ed. Boca Raton, FL: CRC Press; 2011.

32. Rieger M, Rhein L. Surfactants in Cosmetics. 2nd ed. New York: Marcel Decker; 1997.

33. Homendra N, Devi CI. Turbidity studies on mixed surfactant systems in hard water: A new method for estimation of water hardness. Indian J Chem Technol. 2004;11:783-786.

34. Zoller U. Handbook of Detergents, Part E: Applications. Boca Raton, FL: CRC Press; 2008.

35. Celli A, Sanchez S, Behne M, Hazlett T, Gratton E, Mauro T. The epidermal $\mathrm{Ca}^{2+}$ gradient: Measurement using the phasor representation of fluorescent lifetime imaging. Biophys J. 2010;98(5):911-921.

36. Vicanová J, Boelsma E, Mommaas AM, et al. Normalization of epidermal calcium distribution profile in reconstructed human epidermis is related to improvement of terminal differentiation and stratum corneum barrier formation. J Invest Dermatol. 1998;111(1):97-106.

37. Elias PM, Nau P, Hanley K, et al. Formation of the epidermal calcium gradient coincides with key milestones of barrier ontogenesis in the rodent. J Invest Dermatol. 1998;110(4):399-404.

38. Thomas KS, Dean T, O'Leary C, et al. A randomised controlled trial of ion-exchange water softeners for the treatment of eczema in children. PLoS Med. 2011;8(2):e1000395.

39. Thomas KS, Koller K, Dean T, et al. A multicentre randomised controlled trial and economic evaluation of ion-exchange water softeners for the treatment of eczema in children: The Softened Water Eczema Trial (SWET). Health Technol Assess. 2011;15(8):v-vi, 1-156.

40. Togawa Y, Kambe N, Shimojo N, et al. Ultra-pure soft water improves skin barrier function in children with atopic dermatitis: A randomized, double-blind, placebo-controlled, crossover pilot study. J Dermatol Sci. 2014;76(3):269-271. 


\section{Publish your work in this journal}

Clinical, Cosmetic and Investigational Dermatology is an international, peer-reviewed, open access, online journal that focuses on the latest clinical and experimental research in all aspects of skin disease and cosmetic interventions. This journal is included on PubMed. The manuscript management system is completely online and includes a very quick and fair peer-review system, which is all easy to use. Visit http://www.dovepress.com/testimonials.php to read real quotes from published authors

Submit your manuscript here: https://www.dovepress.com/clinical-cosmetic-and-investigational-dermatology-journal 